\title{
Estado de la implementación del \\ Convenio Marco para el Control del Tabaco en la región de las Américas
}

\author{
Rosa Carolina Sandoval, M en Admón Púb, ${ }^{(I)}$ Adriana Blanco, MD. ${ }^{(1)}$
}

\begin{abstract}
Sandoval RC, Blanco A.
Estado de la implementación del Convenio Marco para el Control del Tabaco en la región de las Américas. Salud Publica Mex 2010;52 supl 2:S270-S276.
\end{abstract}

\begin{abstract}
Resumen
Objetivo. Evaluar el estado de implementación de los siguientes mandatos del Convenio Marco para el Control del Tabaco (CMCT) en las Américas: I) precios e impuestos, 2) protección de la exposición al humo de tabaco ajeno, 3) empaquetado y etiquetado,4) publicidad, promoción y patrocinio, 5) cesación y 6) vigilancia. Material y métodos. Se llevó a cabo un análisis descriptivo tomando como fuente el Informe Mundial de la OMS sobre la Epidemia de Tabaquismo. Dicho Informe se sustenta en información legislativa de cada país, la cual es analizada por la OMS y validada por las autoridades nacionales correspondientes. Resultados. La implementación del CMCT en la Región ha sido desigual. Sólo un grupo pequeño de países ha logrado implementar políticas efectivas en al menos dos de los seis mandatos analizados. Conclusión. Si bien la gran mayoría de los países analizados cuenta con legislación en la materia, aún no logra implementar estas medidas en la forma establecida por el CMCT y los estándares internacionales.
\end{abstract}

Palabras clave: tabaquismo; prevención y control; América
Sandoval RC, Blanco A.

Status of the Implementation of the Framework

Convention on Tobacco Control in the Region of the Americas.

Salud Publica Mex 2010;52 suppl 2:S270-S276.

\begin{abstract}
Objective. To assess the status of implementing the following Framework Convention on Tobacco Control (FTCT) mandates in the Americas: (I) Price and tax measures, (2) Protection from exposure to tobacco smoke, (3) Packaging and labeling, (4) Advertising, promotion and sponsorship, (5) Cessation, (6) Surveillance. Material and Methods. Progress is assessed based on the data published in the WHO Reports on the Global Tobacco Epidemic. The WHO Reports are based on national legislation collected at country level, analyzed by WHO and validated by corresponding national authorities. Results. The essay concludes that FCTC implementation has been uneven throughout the Americas. Conclusion. A very small group of countries have been able to implement effective policies for at least two out of the six measures assessed, but the vast majority of countries, while having some existing legislation, have yet to meet the requirements laid out in the FCTC or be consistent with international best practices.
\end{abstract}

Key words: smoking; prevention and control; America
$\mathrm{E}$ Convenio Marco de la OMS para el Control de Tabaco $(\mathrm{CMCT})^{1}$ está en vigencia desde febrero de 2005, 90 días después de que fuera ratificado por el cuadragésimo país. Para los países que en adelante ratificaron o accedieron al CMCT, éste entró en vigor a los 90 días de la fecha de ratificación por el país correspondiente.

Actualmente, ${ }^{2} 168$ países ( $87 \%$ de los estados miembros de la OMS) han ratificado el CMCT. De ellos, 27 países corresponden a la región de las Américas $(77 \%$

(I) Organización Panamericana de la Salud/Organización Mundial de la Salud.Washington DC, EUA.

Fecha de recibido: II de diciembre de 2009 • Fecha de aceptado: 9 de abril de 2010 Solicitud de sobretiros:Rosa Carolina Sandoval. Control de Tabaco. Organización Panamericana de la Salud/Organización Mundial de la Salud. 525 23rd Street, NW Washington DC, 20037, Estados Unidos de América. Correo electrónico: sandovar@paho.org 
de los estados miembros de la OPS). Esto da cuenta del gran aval para el CMCT, expresado tanto en el mundo, como en las Américas.

El CMCT tiene por objetivo proteger a las generaciones presentes y futuras contra las devastadoras consecuencias sanitarias, sociales, económicas y ambientales del consumo de tabaco y de la exposición al humo de tabaco. Para ello, proporciona un marco de medidas que los estados partes habrán de implementar a través de la aprobación de legislación nacional.

En los últimos años se ha observado un auspicioso avance en la aprobación de dicha legislación nacional en algunos países de la región de las Américas. Algunos de ellos se han posicionado ya entre los líderes mundiales en el combate al tabaquismo. El presente ensayo lleva a cabo un análisis descriptivo del estado de la implementación del CMCT en lo referente a seis de sus artículos: 1) Artículo 6 - Medidas relacionadas con los precios e impuestos, 2) Artículo 8 - Protección a la población de la exposición al humo de tabaco ajeno, 3) Artículo 11 Empaquetado y etiquetado de los productos de tabaco, 4) Artículo 13 - Publicidad, promoción y patrocinio del tabaco, 5) Artículo 14 - Medidas de reducción de la demanda relativas a la dependencia y al abandono del tabaco y 6) Artículo 20 - Investigación, vigilancia e intercambio de información.

\section{Material y métodos}

Para el análisis se toma como fuente la información recolectada y publicada en el Informe Mundial de la OMS sobre la Epidemia de Tabaquismo de $2008^{3}$ y 2009.4 Ambos informes recogen información legislativa en el ámbito nacional sobre las seis medidas del paquete MPOWER de la OMS: 1) [Monitor] Vigilar el consumo de tabaco y las políticas para prevenirlo, 2) [Protect $]$ Proteger a la población del humo del tabaco, 3) [Offer] Ofrecer ayuda para el abandono del tabaco, 4) [Warn] Advertir sobre los peligros del tabaco, 5) [Enforce] Hacer cumplir las prohibiciones de publicidad, promoción y patrocinio del tabaco y 6) [Raise] Aumentar los impuestos al tabaco. Este paquete de medidas, lanzado en el 2008 por la OMS, constituye un punto de partida hacia una implementación completa del CMCT en el ámbito nacional.

La información publicada en el Informe de la OMS es recolectada a través de un cuestionario estandarizado, usado por coordinadores nacionales. La información recogida (leyes, reglamentos, resoluciones, etcétera) es revisada y analizada tanto en el ámbito regional como en el mundial y es categorizada de acuerdo con su consistencia con el CMCT y los estándares internacionales. Esta categorización se realiza para cada una de las medidas mencionadas y con base en ello se clasifica a los países en cinco grupos (excepto en el caso de la vigilancia en donde son clasificados en cuatro grupos). Antes de su publicación, la información es validada por las autoridades nacionales de cada país.

Este ensayo culmina con la identificación de aquellas medidas en las que se han logrado menos avances y que en consecuencia constituyen los retos en el futuro combate a la epidemia de tabaquismo en las Américas.

\section{Estado actual de la implementación de artículos seleccionados del CMCT*}

En esta sección se presenta un análisis descriptivo del avance en la implementación de seis medidas contenidas en el CMCT en los países de la región de las Américas, independientemente de su condición de estados partes del CMCT. Estas medidas son: 1) Artículo 6 - Medidas relacionadas con los precios e impuestos, 2) Artículo 8 - Protección a la población de la exposición al humo de tabaco ajeno, 3) Artículo 11 - Empaquetado y etiquetado de los productos de tabaco, 4) Artículo 13 - Publicidad, promoción y patrocinio del tabaco, 5) Artículo 14 - Medidas de reducción de la demanda relativas a la dependencia y al abandono del tabaco y 6) Artículo 20 - Investigación, vigilancia e intercambio de información.

El cuadro I y la figura 1 resumen el estado de implementación de cada una de estas seis medidas en los 35 países de las Américas, según el Informe Mundial de la OMS sobre la Epidemia de Tabaquismo de 2009. Los números corresponden al grupo en que se encuentra cada país en cada medida. La descripción de cada grupo por medida se presenta en el cuadro II. Los grupos reflejan el grado en que determinada medida implementada en el ámbito nacional es consistente con el CMCT y/o efectiva según estándares internacionales.

\subsection{Artículo 6 - Medidas relacionadas con los precios e impuestos}

Tres países (Chile, Cuba y Venezuela) se encuentran en la categoría más alta (grupo 4), en la que los impuestos al tabaco están por encima del 75\% del precio de venta al por menor. Nueve países aplican impuestos que representan entre 51 y $75 \%$ de dicho precio (grupo 3), en 18 países este porcentaje está entre $25 \%$ y 50\% (grupo 2) y en cuatro países es de menos de $25 \%$ (grupo 1). Para un país no se notificaron datos (grupo 0).

\footnotetext{
* El Informe de la OMS sobre la Epidemia Mundial de Tabaquismo de 2009 tuvo como fecha de cierre diciembre de 2008. Esto significa que cualquier cambio en la legislación ocurrido después de esa fecha no está reflejado en el Informe de 2009.
} 
Si bien, entre 2008 y 2009, en algunos países el porcentaje que los impuestos al tabaco representan del precio final aumentó (Bahamas, Brasil, Colombia, Guyana, Jamaica, Nicaragua, Surinam y Trinidad y Tobago), ${ }^{5}$ ningún nuevo país se sumó al grupo en la categoría más alta.
2.2 Artículo 8 - Protección a la población

de la exposición al humo de tabaco ajeno

Cinco países (Canadá, Colombia, Guatemala, Panamá, Uruguay) se encuentran en la categoría más alta, es decir, en ellos existe legislación sobre protección a la

Cuadro I

Estado de implementación de algunos mandatos del CMCT en las Américas, 2009*

\begin{tabular}{|c|c|c|c|c|c|c|}
\hline Pais & Impuestos & $A L H T^{* *}$ & Advertencias & Publicidad & Cesación & Vigilancia \\
\hline Antigua y Barbuda & 2 & I & I & I & 2 & I \\
\hline Argentina & 3 & 1 & 1 & 1 & 3 & 3 \\
\hline Bahamas & 1 & 1 & 1 & 3 & 2 & 1 \\
\hline Barbados & 2 & 1 & 1 & 1 & 2 & 1 \\
\hline Belice & 2 & 1 & $\mathrm{I}$ & 1 & 2 & 2 \\
\hline Bolivia & 2 & 3 & 4 & 1 & 2 & 1 \\
\hline Brasil & 3 & 1 & 4 & 3 & 4 & 1 \\
\hline Canadá & 3 & 4 & 2 & 1 & 2 & 3 \\
\hline Chile & 4 & 1 & 2 & 3 & 2 & 1 \\
\hline Colombia & 2 & 4 & $\mathrm{I}$ & 1 & 2 & 0 \\
\hline Costa Rica & 3 & 1 & $\mathrm{I}$ & 1 & 3 & 2 \\
\hline Cuba & 4 & 2 & 2 & 1 & 3 & 0 \\
\hline Dominica & 2 & 1 & 1 & 1 & 2 & 1 \\
\hline Ecuador & 3 & 2 & 2 & 1 & 3 & 1 \\
\hline El Salvador & 2 & 2 & I & I & 3 & 2 \\
\hline Estados Unidos de América & 2 & 1 & 1 & 1 & 2 & 3 \\
\hline Granada & 2 & 1 & 1 & 1 & 2 & 1 \\
\hline Guatemala & 3 & 4 & 1 & 1 & 3 & 2 \\
\hline Guyana & 2 & 1 & 2 & 1 & 2 & $\mathrm{I}$ \\
\hline Haití & 0 & 1 & $\mathrm{I}$ & $\mathrm{I}$ & 2 & 0 \\
\hline Honduras & 2 & 2 & 1 & 1 & 2 & 1 \\
\hline Jamaica & 2 & 1 & 2 & 1 & 3 & 1 \\
\hline México & 3 & 1 & 2 & $\mathrm{I}$ & 3 & 1 \\
\hline Nicaragua & 1 & 1 & $\mathrm{I}$ & $\mathrm{I}$ & 2 & 0 \\
\hline Panamá & 2 & 4 & 4 & 4 & 3 & 2 \\
\hline Paraguay & 1 & 1 & 1 & 1 & 3 & 2 \\
\hline Perú & 2 & 2 & $\mathrm{I}$ & 1 & 2 & $\mathrm{I}$ \\
\hline República Dominicana & 3 & 1 & 1 & 1 & 2 & 2 \\
\hline Saint Kitts y Nevis & 2 & 1 & 1 & 1 & 2 & 0 \\
\hline Santa Lucía & $\mathrm{I}$ & 1 & $\mathrm{I}$ & 1 & 2 & $\mathrm{I}$ \\
\hline San Vicente y las Granadinas & 2 & 1 & 1 & 1 & 2 & $\mathrm{I}$ \\
\hline Surinam & 2 & 1 & 1 & 1 & 2 & 2 \\
\hline Trinidad y Tobago & 2 & 1 & $\mathrm{I}$ & 1 & 2 & $\mathrm{I}$ \\
\hline Uruguay & 3 & 4 & 4 & 3 & 4 & 3 \\
\hline Venezuela & 4 & 2 & 4 & 1 & 3 & 1 \\
\hline
\end{tabular}

* Ver el cuadro II para una descripción de los indicadores usados en este cuadro

*** Ambientes libres de humo de tabaco

ALHT: ambientes libres de humo de tabaco

Fuente: Referencia 4 


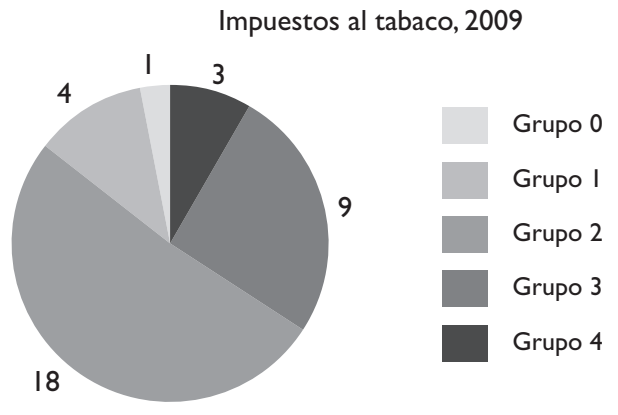

Advertencias sanitarias, 2009

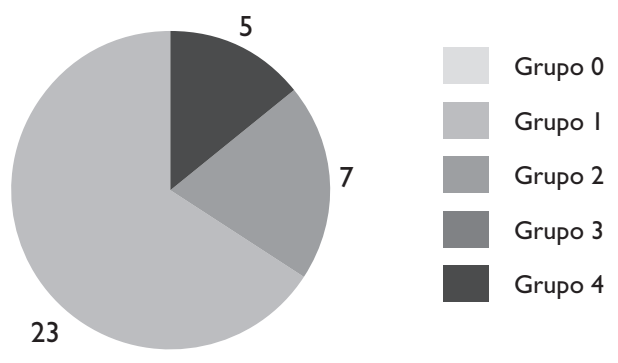

Cesación, 2009
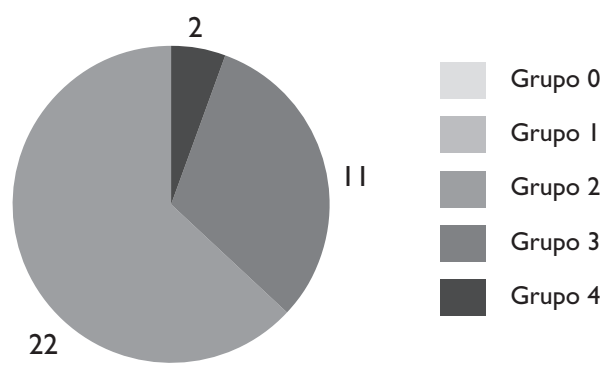

Ambientes libres de humo de tabaco, 2009

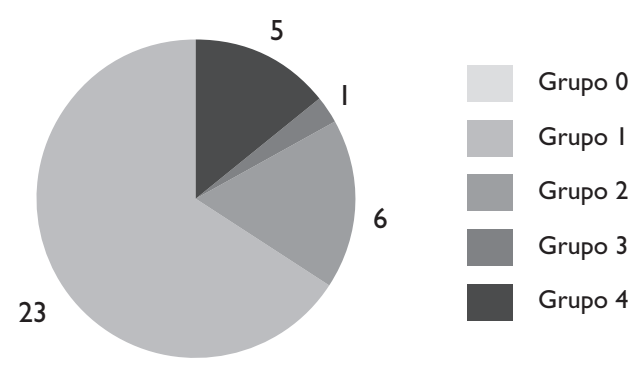

Publicidad, promoción y patrocinio, 2009
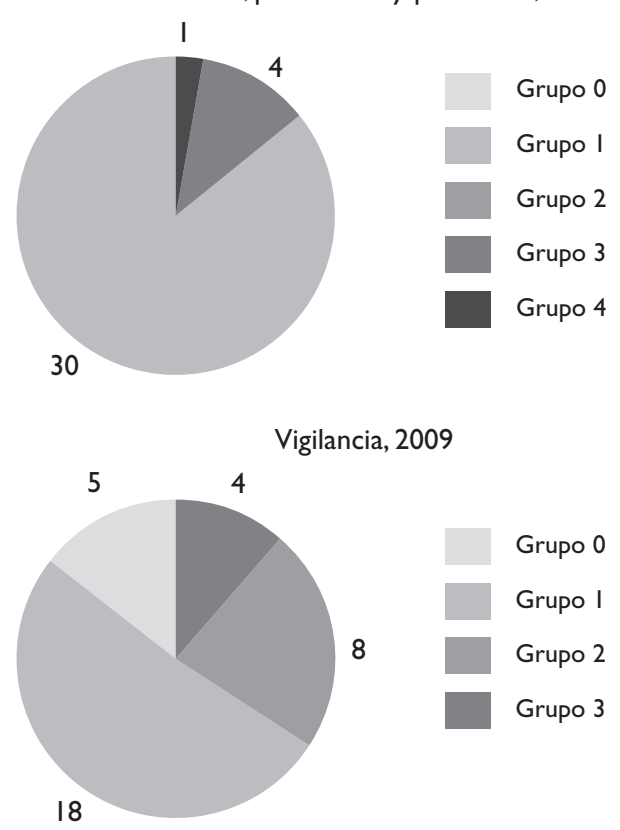

Fuente: Referencia 4

Figura I. Estado de Implementación de algunos mandatos del CMCT en las Américas, 2009

exposición al humo de tabaco ajeno que establece una prohibición de fumar en todos los lugares públicos y de trabajo cerrados, sin excepción. En todo el ámbito nacional, o al menos $90 \%$ de su población, está cubierta a través de legislación subnacional. Un país cuenta con una prohibición de fumar en de 6 a 7 tipos de lugares públicos, ${ }^{*}$ pero no en todos. Seis países cuentan con este tipo de prohibición ( 3 a 5 tipo de lugares públicos)

\footnotetext{
* Los tipos de lugares públicos son: establecimientos de salud, establecimientos educativos excepto universidades, universidades, oficinas de gobierno, interiores de oficinas privadas, restaurantes, bares y pubs, transporte público y el resto de los otros lugares públicos.
}

y 23 países cuentan con este tipo de prohibición en un máximo de dos tipos de lugares públicos.

Entre 2008 y 2009, el principal y más significativo cambio constituye que cuatro países se unieron a Uruguay en la categoría más alta.

\subsection{Artículo 11 - Empaquetado e etiquetado de los productos de tabaco}

Cinco países (Bolivia, ${ }^{*}$ Brasil, Panamá, Uruguay y Venezuela) se encuentran en la categoría más alta, es

\footnotetext{
* La política ha sido aprobada pero al 31 de diciembre de 2008. Tanto la regulación como la implementación están pendiente.
} 
Cuadro II

DESCRIPCIÓN DE LOS GRUPOS DEL CUADRO I

Ambientes libres de humo de tabaco

No se reportaron datos

Hasta dos tipos de lugares públicos libres de humo de tabaco

De 3 a 5 tipos de lugares públicos libres de humo de tabaco

De 6 a 7 tipos de lugares públicos libres de humo de tabaco

Todos los lugares públicos libres de humo de tabaco (o al menos $90 \%$ de la población cubierta por legislación subnacional)

Cesación

No se reportaron datos

Ninguno

Tratamiento de sustitución con nicotina (TSN) y/o algún servicio de cesación

TSN y/o algún servicio de cesación y al menos uno con cobertura de gastos

Línea telefónica nacional y TSN y servicios de cesación con cobertura de gastos

Advertencias

No se reportaron datos

Advertencia que cubre menos de $30 \%$ o ninguna advertencia

Advertencia de $\geq 30 \%$ pero sin imágenes y otras características deseadas

Advertencia de $31-49 \%$ incluyendo imágenes y otras características deseadas

Advertencia de $\geq 50 \%$ incluyendo imágenes y características deseadas

Publicidad

No se reportaron datos

Ausencia absoluta de una prohibición o la prohibición no cubre al menos TV, radio y prensa nacionales

Prohibición que cubre únicamente TV, radio y prensa nacionales

Prohibición que cubre TV, radio y prensa nacionales a la vez que algunas otras formas de publicidad directa o indirecta pero no todas

Prohibición de todas las formas de publicidad directa e indirecta

Impuestos

No se reportaron datos

$\leq 25 \%$ del precio al por menor corresponde a impuestos

26-50\% del precio al por menor corresponde a impuestos

$5 \mathrm{I}-75 \%$ del precio al por menor corresponde a impuestos

$>75 \%$ del precio al por menor corresponde a impuestos

Vigilancia

No existe data o data no reciente o data que no es a la vez reciente y representativa

Data reciente y representativa para ya sea para jóvenes o para adultos

Data reciente y representativa tanto para jóvenes como para adultos

Data reciente, representativa y periódica tanto para jóvenes como para adultos

Fuente: Referencia 4

decir, cuentan con advertencias sanitarias que cubren al menos 50\% de las caras principales de los paquetes, con una prohibición de términos engañosos como "suave" y "ligeros", y con los siete criterios recomendados por el CMCT y la evidencia internacional sobre advertencias efectivas. Estos siete criterios son: 1) que la legislación incluya mensajes específicos, 2) que aparezcan en los paquete individuales así como en la parte exterior de todo empaquetado para venta al por menor, 3) que describan efectos dañinos específicos en la salud, 4) que sean grandes, claras, visibles y legibles, especificándose colores y tamaño de letra, 5) que roten, 6) que estén 
escritas en el idioma o los idiomas principales del país y 7) que incluyan imágenes.

Ningún país se encuentra en la segunda categoría con advertencias que cubren entre 31 y $49 \%$ de las caras principales, incluyendo imágenes. Siete países cuentan con advertencias que cubren al menos $30 \%$ de las caras principales del paquete, pero no incluyen imágenes $u$ otros de los criterios deseados. Y 23 países establecen advertencias que cubren menos de $30 \%$ de las caras principales o no cuentan con este tipo de regulación.

Entre 2008 y 2009, Bolivia y Panamá se unieron al grupo de países en la categoría más alta.

\subsection{Artículo 13 - Publicidad, promoción y patrocinio del tabaco}

Sólo un país (Panamá) se encuentra en la categoría más alta, es decir, ha establecido una prohibición completa de la publicidad y promoción de los productos de tabaco y patrocinio por parte de la industria tabacalera.

Cuatro países cuentan con prohibiciones de la publicidad y promoción en la televisión, radio y prensa nacionales, así como en algunos otros medios, pero no en todos. Ningún país cuenta con una prohibición que incluya únicamente la televisión, el radio y la prensa nacionales y 30 países cuentan con algunas pero éstas no incluyen a la vez televisión, radio y prensa nacionales* o no cuentan con ningún tipo de prohibición.

Antes de 2008, ningún país de las Américas contaba con una prohibición completa e integral.

\subsection{Artículo 14 - Medidas de reducción de la demanda relativas a la dependencia y al abandono del tabaco}

En dos países de la región (Brasil y Uruguay) existe una línea telefónica nacional de ayuda al abandono del tabaquismo, así como disponibilidad de tratamiento por sustitución de nicotina y de servicios clínicos de cesación y ambos cuentan con cobertura de gastos. En 11 países hay disponibilidad de tratamiento por sustitución de nicotina y de servicios clínicos de cesación, pero sólo uno de ellos tiene cobertura de gastos. En 22 países hay disponibilidad, ya sea de tratamientos por sustitución de nicotina y/o de servicios clínicos de cesación, pero ninguna cuenta con cobertura de gastos.

\footnotetext{
* Es necesario notar que la prohibición de publicidad en un medio debe ser integral y sin excepciones para ser considerada como tal. Por ejemplo, si existe una prohibición de publicidad en revistas con excepción de revistas para adultos, entonces ésta no es considerada como una prohibición en revistas.
}

Entre 2008 y 2009 ningún país se sumó al grupo de países en la categoría más alta.

\subsection{Artículo 20 - Investigación, vigilancia e intercambio de información}

Cuatro países (Argentina, Canadá, Estados Unidos de América y Uruguay) se encuentran en la categoría más alta, es decir, cuentan con datos sobre prevalencia en adultos y jóvenes que son recientes, representativos y recolectados de manera periódica.

Ocho países cuentan con datos sobre prevalencia en adultos y jóvenes que son recientes y representativos pero hasta el momento no han sido recolectados de manera periódica. Asimismo, 18 países cuentan con datos sobre prevalencia, ya sea para adultos o para jóvenes, pero no para ambos y éstos son recientes y representativos, pero no periódicos. Los cambios entre 2008 y 2009 no se discuten, dado que los criterios de agrupación de los países fueron modificados en el Informe de la OMS.

\section{Discusión}

La implementación del CMCT en la región de las Américas ha sido desigual. Sólo un grupo pequeño de países ha logrado implementar políticas efectivas en al menos dos de los seis mandatos analizados en este ensayo. La gran mayoría de países, si bien cuenta con legislación en la materia, aún no logra implementar estas medidas en la forma establecida por el CMCT y los estándares internacionales.

Los países que han logrado tener más progreso en aprobar legislación nacional consistente con los estipulados del CMCT lo han logrado fundamentalmente en los artículos 11 y 8 , sobre empaquetado de productos de tabaco y protección contra la exposición al humo de tabaco ajeno, respectivamente. El Artículo 8 es además aquel en el que se observa mayor avance entre 2008 y 2009.

En el otro extremo, los artículos 6 y 13, sobre impuestos al tabaco y prohibición de la publicidad, promoción y patrocinio, son aquellos en donde un menor número de países han logrado aprobar legislación efectiva. Si bien algunos países han aprobado nuevas regulaciones o decretos sobre este tema, ha sido difícil lograr colocarse en la categoría más alta de efectividad según la OMS.

El intercambio de experiencias exitosas, la creación o fortalecimiento de unidades nacionales de control de tabaco y la inclusión del tema de control de tabaco en la agenda de los organismos de integración subregional son tres de las acciones que permitirán a los países de las Américas continuar avanzando en el combate a la epidemia de tabaquismo, tanto nacional como regionalmente. 
Declaración de conflicto de intereses

Declaramos no tener conflicto de intereses.

\section{Referencias}

I. Organización Mundial de la Salud. Convenio Marco de la OMS para el Control de Tabaco. Ginebra: Organización Mundial de la Salud, 2003.

2. Organización Mundial de la Salud. Convenio Marco de la OMS para el Control de Tabaco. Lista de Partes [consultado: 2010 marzo]. Disponible en:www.who.int/fctc/signatories_parties/en/index.html.
3. Organización Mundial de la Salud. Informe OMS sobre la Epidemia Mundial de Tabaquismo, 2008. Plan de medidas MPOWER. Ginebra: Organización Mundial de la Salud, 2008.

4. World Health Organization.WHO Report on the Global Tobacco Epidemic, 2009. Implementing smoke-free environments. Geneva:World Health Organization, 2009.

5.World Health Organization. WHO Report on the Global Tobacco Epidemic, 2009. Implementing smoke-free environments. Appendix IV [consultado: 2010 marzo]. Disponible en: www.who.int/tobacco/ mpower/2009/appendix_iv/en/index.html. 